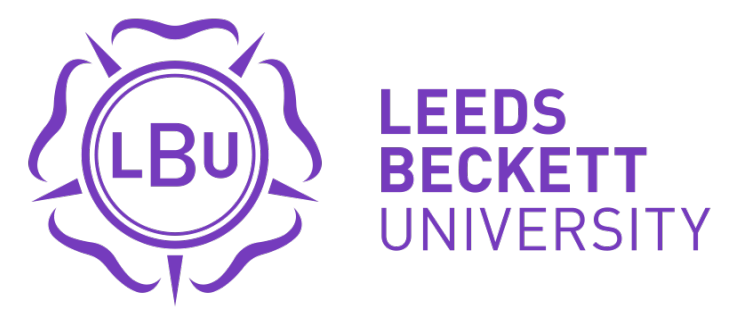

Citation:

Sharma-Brymer, V and Brymer, E and Gray, T and Davids, K (2018) Affordances guiding Forest School practice: The application of the Ecological Dynamics approach. Journal of Outdoor and Environmental Education, 21 (1). pp. 103-115. ISSN 2206-3110 DOI: https://doi.org/10.1007/s42322017-0004-3

Link to Leeds Beckett Repository record:

https://eprints.leedsbeckett.ac.uk/id/eprint/4788/

Document Version:

Article (Accepted Version)

The aim of the Leeds Beckett Repository is to provide open access to our research, as required by funder policies and permitted by publishers and copyright law.

The Leeds Beckett repository holds a wide range of publications, each of which has been checked for copyright and the relevant embargo period has been applied by the Research Services team.

We operate on a standard take-down policy. If you are the author or publisher of an output and you would like it removed from the repository, please contact us and we will investigate on a case-by-case basis.

Each thesis in the repository has been cleared where necessary by the author for third party copyright. If you would like a thesis to be removed from the repository or believe there is an issue with copyright, please contact us on openaccess@leedsbeckett.ac.uk and we will investigate on a case-by-case basis. 


\title{
Affordances guiding Forest School practice: The application of the Ecological Dynamics approach
}

\section{Sharma-Brymer, Vinathe; Brymer, G. E.; Gray, Tonia; Davids, Keith}

\begin{abstract}
Forest School focuses on child development underlining nature-connection and play pedagogy. Practitioners facilitate child-led learning through a deep observation approach. However, challenges and assumptions exist in such approaches. Additionally, a critical examination of the practice reveals that it may be lacking a solid theoretical underpinning that can respond to diverse contexts and participants while escaping a one-size-fits-all approach encouraged by commercialisation. Ecological Dynamics offers a theoretical framework that has the potential to guide Forest School practice and clarify its effectiveness. Specifically, notions of affordances combined with analysis at the level of personenvironment relationships could guide future design and implementation of activities. Benefits could include realising and attuning to affordances which have sociocultural and individual connotations, thereby respecting local cultures and their community resources. The role of the Forest School practitioner becomes one of facilitating diverse populations in their perception of affordances in nature for individualised benefits, including well-being.
\end{abstract}

Keywords: Forest School, Ecological Dynamics, affordances, person-environment relationships

\section{Suggested running header: Affordances guiding Forest School practice}

\section{Introduction}

A growing body of research has investigated Forest School (FS) practice (for example, Harris, 2017; Knight, 2009, 2011; Maynard, 2007; O’Brien \& Murray, 2006, 2007; Waite, Bølling, \& Bentsen, 2016). FS emerged from Danish influences that incorporated learning outside the classroom known as udeskole. Initially catering for early childhood education in the Danish context, the FS concept then expanded to include broader age groups and differential needs, in particular older children with emotional and behavioural issues (O'Brien, 2009; O'Brien \& 
Murray, 2006). Emerging as a specific development-focused framework it drew from learning theories, play pedagogy and outdoor education (Massey, 2005). FS aims to provide regular hands-on learning opportunities for children to have contact with the natural environment over an extended period of time, believed to enhance development and well-being.

Over the years, the conceptual ideas and practices of FS have become institutionalised with registration available via different bodies (Leather, 2018). The process of creating a national governing body in the UK, "to accredit professional standards for delivery and to regulate training standards" (Knight, 2011, p. 590), has further ossified FS, the message being that educators should qualify as FS practitioners, even if they already effectively incorporate nature-based learning activities in their practice.

The current trajectory of FS reveals three main points for critical discussion. Firstly, the structured methodology of learning techniques in the educational component of the FS model challenges historically, socially and culturally situated outdoor education practices in the UK. Secondly, the commodification of FS sits somewhat uncomfortably with the udeskole practice of taking children's learning outside of classrooms, not necessarily following predetermined techniques or accessing a forest location (Bentsen, Ho, Gray, \& Waite, 2017; Bentsen, \& Jensen, 2012). Thirdly, the original Scandinavian philosophical influences are not well reflected in the UK FS model which overemphasises child development, understood as complying with an outcomes-based educational framework. Additionally, efforts to market the UK model of FS by exporting it to different countries neglects rich local cultural heritages, knowledges and perspectives. This particular situation may impede ongoing efforts to decolonise Eurocentric knowledge in school curricula (Hart, Whatman, McLaughlin, \& SharmaBrymer, 2012). It may also lead to new forms of inequalities in children's educational experiences.

Responding to the above critical points, this paper argues that FS practice, as it is now, needs to embrace sociocultural diversity, to respect and respond to local knowledge(s) and perspectives, and to focus on person-environment relationships. To achieve these, the FS approach needs to be informed by a theoretical perspective that can guide context-specific practices. Based on this premise, we argue for Ecological Dynamics (ED) as a theoretical 
framework which emphasizes the design of unique learning experiences emergent from the landscape of affordances in a typified woodland environment.

In our first section, we briefly summarise the origins of FS, and point out its relevance and current issues in order to contextualise our argument for an ED framework. The second section will outline the ED theoretical perspective and discuss its application to FS, highlighting the importance of affordances.

\section{Development of FS in the UK}

The staff at Bridgwater College, England, incorporated FS understandings in their early years education programme in the 1990s. They studied and were impressed with the Danish udeskole where children's learning experiences outside the classroom were considered significantly influential in childhood. In udeskole the connection with nature shifts learning outside, using diverse stimuli resulting in specific educational experiences (Bentsen, et al., 2017; Bentsen \& Jensen, 2012; Bentsen, Mygind \& Randrup, 2008; Waite, Bolling \& Bentsen, 2016). Udeskole has its roots in the Scandinavian philosophy of friluftsliv (Aadland, Arnesen \& Nerland, 2009; Bentsen \& Jensen, 2012; Harris, 2017; Maynard 2007). Friluftsliv or 'free air life' emphasises a person feeling free in nature accompanied by a spiritual connection with natural landscapes, expressed in a slow and gradual accumulative lived experience (Gelter, 2000; 2009). Friluftsliv embraces being part of the natural world, thereby having similar underpinnings to many indigenous perspectives on human-nature relationships (Stewart, 2008; Whap, 2001). However, some debate has been raised about the dilution of the philosophical meaning of friluftsliv through udeskole (Gelter, 2000, 2009; Gurholt, 2014), mainly because friluftsliv requires an ongoing, immersed, living experience in nature, which udeskole may not be able to fully emulate. Udeskole experiences are often set in external social, economic, political and geographical contexts including forests, farms, factories, museums and community activities, complementing school curriculum (Bentsen et al., 2008; Jordet, 2009). As such, Danish udeskole does not entirely embrace living outdoor experience or the spiritual connection to nature. And, as Waite et al. (2016) point out, there are marked differences between FS and udeskole. FS is often considered an antidote to nature deprivation in the UK, whereas in Denmark udeskole is a "bottom-up counterculture of traditional education" (p. 872). Nature deprivation amongst children in the UK is often linked to how 
adults construct childhood and perceive risks (Gill, 2007). Besides over-reacting to safety, adults disapproving children's presence in the outdoors without an accompanying adult has further accentuated children's disconnection with nature (Muñoz, 2009). FS's apparent role as an antidote to nature deprivation raises issues of adults re-shaping childhood, and therefore calls for a newer understanding of its effectiveness.

\section{Structured FS practice in the UK: Some issues}

FS was formalised in 1995 as a study course in early years education at Bridgwater College (Cree \& McCree, 2012; Davies, 2013; Knight, 2009). FS concepts, courses, practice, programmes and structure then spread across England and Wales. Independent bodies such as the Forest School Association, along with Forest Schools, Local Authorities, the Forestry Commission and a number of individuals have trained thousands as FS leaders. Typically, trainees at Level 3 are initially taught methodology, techniques and child development theories over 5-7 days. Following this they develop their portfolio by working with children (placement), consolidate their theoretical knowledge and practise techniques of tool use, fire and other bush craft activities. In the final phase they are assessed for their practical skills and portfolio.

FS training and development courses have drawn from Playwork Wales, Bob Hughes's "play types" (2002), Ferre Laevers' "signs of well-being" (1999), and Goleman's "emotional intelligence" (1998). Children's self-esteem, confidence and self-awareness along with prominent aspects of physical, social, emotional and communication development are observed and documented. The most popular activities are using tools, making fire, den/shelter building, nature-exploration, team-games, environmental games, and nature arts and crafts.

Several conceptual and practical skills frameworks such as ecotherapy, sustainability, biophilia, bush craft, and outdoor and adventure education have informed FS practice (Harris, 2017; Knight, 2011; Leather, 2016; Maynard, 2007). The process of creating a national governing body in order to formalise training and register professionals has remodelled FS, repositioning it as an educational product (Leather, 2018). This has created the belief amongst educators of the need to qualify as a Level 3 FS practitioner in order to legitimately adopt FS 
practices. In agreement with Leather, (2018), we believe that commercialisation and commodification of FS might standardise children's experiences in the outdoor environment to such an extent that it may become another performance-oriented system seeking outcomes on a par with the school education system.

Different to the Scandinavian udeskole and friluftsliv, FS in the UK has the tendency to overemphasise the adult's role in developing a child's self-esteem (Leather, 2018; Waite et al., 2016). FS practitioners, although seen as facilitators, work to enhance children's confidence, self-awareness and self-regulation. FS is thus positioned as an avenue for the development of personal attributes deemed to be appropriate for a child's development, which may sometimes be in tension with philosophical perspectives that emphasise connection to nature. For some, this developmental trajectory is problematic. The theoretical understanding underpinning FS practice remains weak, employing reference to udeskole and friluftsliv to strengthen its affordances in nature.

Hence there is need for a theoretical framework that recognises these nuances in order to guide practice and further research. Within this context we argue that the Ecological Dynamics (ED) theoretical framework, with its focus on affordances (Gibson, 1979) and the person-environment scale of analysis (Brymer \& Davids, 2014), has the potential to guide the design and implementation of FS. The benefits obtained from FS practice, as we argue in the following section, are about realising and attuning to affordances which have sociocultural and individual expressions.

\section{An overview of Ecological Dynamics (ED) as a theoretical perspective}

FS practice would benefit from further theorisation to help realise its broad potential to respond to different sociocultural and individual requirements. Appropriate theoretical understandings will encapsulate and develop current diverse approaches to research and practice in FS applications, allowing for individual differences and cultural requirements. In this section we outline and argue for ED as a theoretical framework that enhances understandings of FS. 
Ecological Dynamics stems from ecological psychology and dynamical systems theory (Brymer \& Davids, 2012, 2014). ED conceptualises an individual as a complex dynamic system composed of many interdependent, interacting subsystems or domains (e.g., physical, cognitive, social, emotional, spiritual and so on). It is a well-established framework for understanding human learning and behaviour in many associated fields including sport, adventure, environmental education, experiential learning, and health (Brymer, Davids, \& Mallabon, 2014; Brymer \& Davids, 2016; Clough, Houge McKenzie, Mallabon \& Brymer, 2016; Davids, Araújo \& Brymer, 2016; Sharma-Brymer, Brymer, \& Davids, 2015). The ED framework is, we suggest, suitable for guiding FS practice and research because it proposes that learning and behaviour are grounded in an interactive and mutually reinforcing relationship between the person and environment. ED is a functional approach which positions understanding of human behaviours in the person-environment relationship, where the environment captures both social and physical constraints on behaviour (Brymer \& Davids, 2012; 2014; Dunwoody, 2006; Newell, 1986). Individual behaviours are interpreted in context.

There are a number of key conceptual ideas in the ED framework that are useful for capturing FS understandings - affordances, form of life, effectivities and representative design. Affordances are described as invitations for action stemming from relationships between an individual and their environment uniting the objective nature of the environment with the subjective nature of the individual (Gibson, 1979; Withagen, De Poel, Araújo, \& Pepping, 2012). The notion of affordance does not suggest that all invitations are always good for the individual, as sometimes affordances can be harmful:

The affordances of the environment are what it offers the animal, what it provides or furnishes, either for good or ill. The verb to afford is found in the dictionary, but the noun affordance is not. I have made it up. I mean by it something that refers to both the environment and the animal in a way that no existing term does. It implies the complementarity of the animal and the environment (Gibson, 1979, p. 127)

An environment described in terms of affordances changes the emphasis from a description based on appearance (what the environment looks like, e.g. shape and colour) to an active and functional description, which illuminates behaviours that emerge from continuous 
interactions with an environment. For example, landscapes traditionally described in terms of structural features, such as colour, height, length, aesthetics and so forth, are now deemed to consist of climbable features, apertures, gaps, paths to traverse, openings that offer shelter opportunities, mouldable materials for use as tools, textured and uneven surfaces that offer support or the potential for falls, flat surfaces, smooth surfaces, graspable surfaces, attached objects, and non-rigid objects to negotiate (Brymer et al., 2014). From an ED perspective, affordances can also be social, emotional and cognitive.

The notion of a form of life describes both the common and potential behaviour available to a specific group of organisms (e.g., human beings) and how the group interacts in and with the world around them (Gibson, 1979). Human habits, customs, beliefs, attitudes, feelings, desires, ways of doing things that prevail in everyday life encompass a form of life. This might manifest as cultural tendencies or patterns of behaviour (Rietveld \& Kiverstein, 2014). Effectivities are the skills, capacities and capabilities that an individual might bring to an interaction with an environment (Stoffregen, 2003). Effectivities can be constrained by the environment (such as urban design, and cultural or social mores or habits), which might mean that while a form of life has the capacity to realise certain affordances, an individual's effectivities could be impoverished by an environment. Effectivities are time-bound and can be developed as a result of positive environmental constraints. When effectivities complement affordances they support the perception and possible realisation of affordances.

\section{Affordances and individualised learning}

Ecological Dynamics conceptualises a learner as a complex, open system in nature. Learners enter learning contexts with dispositional characteristics (e.g. physical, cultural, emotional and psychological influences) that act to constrain the development of new behaviour (Chow, Davids, Hristovski, et al., 2011). Learning is understood as individualised and nonlinear characterised by regressions and progressions, skips, jumps and transitions, as well as periods of stability. Each learner realises relatively unique behaviours in his/her own time. Learning is an iterative process of perceiving and acting upon affordances impinging on each individual during his/her personal development. 
From the ED perspective, effective learning emerges from the dynamic person-environment relationship. Emergent behaviours are neither completely predictable nor random. Learners achieve stable learning patterns based on the interaction between individual constraints and those inherent in the task and environment. The implication of this idea is that educators need to design activities where the task and environment are conducive to the emergence of intended learning outcomes. Designers of learning experiences need to recognise appropriate affordances based on intended outcomes. For example, if the intention is to facilitate FS for personal development and enhance connection to nature then the tasks in the FS learning episode and 'space' need to provide a valid simulation which represents the relevant characteristics in everyday life, particularly the information available to support actions. Representative learning design emphasises the relationship between effectivities and the environment and refers to the process of ensuring that key learning elements in the real world are accurately represented in the design of the learning space. This does not reflect a requirement for physical representation but that essential information in the everyday world (e.g. social, emotional, communication) should be accurately reflected.

For example, for school-based FS programmes to be effective the programme design would work best if it represents the everyday context of the school group. This notion suggests that FS practitioners must not only develop a mastery of knowledge and experience in specific activities but also a profound grasp of key, relevant information inherent in a learner's everyday life. FS practitioners can use this knowledge and mastery to design effective, relevant learning experiences ensuring that a learning context is a faithful simulation which is representative of a behavioural context (Davids, Button \& Bennett, 2008; Pinder, Davids, Renshaw \& Araújo, 2011). FS practitioner must recognise the most important physical, psychological, social and cultural processes that exist in an everyday environment and design tasks that represent the everyday experiences. It is important to determine the constraints apparent in the life context of the individual in order to design a programme that best meets the individual's behavioural needs. Hence identifying affordances not only in a woodland environment but also from within the learner's community life enriches individual learning experiences as more authentic and away from classroom teaching.

\section{Constraints and affordances}


Environmental, task or individual constraints that limit the rate of learning and development in an individual are termed 'rate limiters.' For example, rate limiters might include emotional readiness of participants, leader or practitioner's capacities or task relevance. Equally, the ED perspective suggests that learning design and the teaching methodology or focus might become rate limiters, which supports a more expanded understanding of learning (Maitney, 2002). Typical rate limiters include the physical learning environment, and relationship between the facilitator and participants. A skilled FS practitioner can manipulate activities to limit or indeed remove the effect of rate limiters that are most obviously hindering learning. However, this means that practitioners need to be skilled enough at determining an individual's needs in order to manipulate the task (or environmental) constraints to best draw out the intended learner-centred learning process. A FS context that focuses on differentiating the forest learning space from the everyday space might act as a rate limiter if the differentiation becomes the focus. However, this notion does not necessarily mean that the FS learning space needs to be physically the same as the everyday performing space; merely that the most salient affordances need to be apparent in the learning space for long term and relevant learning to take place.

A key question for the FS provider is: What does this specific object, feature, situation or context offer each individual learner? An ecological approach differentiates between knowing something abstractly (providing knowledge about something) and a deeper, more profound experiential knowledge of an environment (knowledge of what an environment offers or invites) (Gibson, 1979). The fundamental nature of this differentiation emphasises the importance of active learning in the environment (Araújo \& Davids, 2011; Gibson, 1979). The implication of this idea is that learners need to be placed in representative learning environments where they can become attuned to information which provides knowledge of the environment to enable functional behaviours to emerge such as perceptions, emotions, as well as opportunities for decision making and action. Affordances capture the deeply intertwined relations between cognition, perception and action, which may change as a function of time and context, for instance with experience and expertise in a specific task.

The coupling of action and perception systems is strengthened through a process of attunement to relevant information to gain knowledge and support functional behaviours. 
Effective perception-action couplings emerge from effective learning leading to sustainable behaviour changes, and the learning context must provide simulations which are representative of the everyday activity. Reducing an intended behaviour to decomposed parts (to artificially reduce the information load on a learner) or designing tasks that encourage behaviours to emerge out of context breaks up this process of information-behaviour coupling. These traditional aspects of learning design can prevent learners from basing their actions on knowledge of the environment and can prevent them from using actions to gain further knowledge. The result may be an unproductive development of less functional behaviours that may not transfer to everyday life contexts.

\section{Application of Ecological Dynamics to FS practice}

Ecological Dynamics encourages a more individualised approach to learning and provides a useful framework for designers of learning to make the experience for the learner more personalised and meaningful. ED proposes that we are embedded within a landscape of affordances or invitations for action that can support our continuous interactions with an environment (Gibson, 1979). However, the everyday life context often means that affordances available to a specific individual are impoverished when compared to the rich potential available to the form of life. As individuals we are often limited in our capacity to realise our potential within a form of life, which means we may only perform a small percentage of what we are capable of doing in a particular situation (Stoffregen, 2003). A human being's everyday effectivities are limited as a result of the everyday life context involving commonplace issues. FS is a wonderful opportunity and an ideal medium for the expansion of effectivities. As such, while the individual becomes skilled at acting on potential affordances in the everyday life context, an expanded landscape of affordances would include a richer array of possibilities. If effectively designed, the FS experience facilitates a dynamic person-environment relationship that has the potential to expand effectivities in sociocultural contexts. In this instance the cultural context might be both the current everyday cultural context and the socio-historical context of the individual learners. FS provides a richer landscape of affordances that augments variability of experience as the learner learns to adapt his or her behaviour in order to realise an array of affordances that might not be available in the everyday life of the individual, but that are nevertheless available to the form of life (Rietveld \& Kiverstein, 2014). 
In the above context, FS practitioners will need to carefully consider the goals of the learning process, key affordances, form of life and individual effectivities based on the personenvironment relationship in order to design effective learning experiences. This suggests that a one-size-fits-all approach is not appropriate, as affordances are more complex than such an approach allows. For example, the environment might afford a deeper relationship with nature for the learner attuned to perceiving and acting upon that affordance. However, the same physical environment might cause stress for the person attuned to nature as dirty, wet and cold; or social interaction for the person attuned to perceiving social affordances. Based on this premise, the FS practice provides access to a rich landscape of affordances which can be realised differently for different people with different effectivities and needs (Roe \& Aspinall, 2011; Said, 2012). As such, while the activity might look the same from the outside the invitations will differ and depend on effectivities of each person. In this way, the relational aspects are emphasised and the learner extends their capacity to realise some of the spectrum of affordances that might not be available in their everyday life context, such as invited through the muddy kitchen activity (Bruineberg \& Rietveld, 2014). The challenge for the FS practitioner is to represent the everyday life context so that the learning continues beyond the specific learning context and is sustained in the learner's everyday life context. As individualised learning is accentuated, FS practice escapes the uniformity that Leather (2016) highlights.

\section{Designing affordances}

As affordances can be obscured (Ewert, Sibthorp \& Sibthorp, 2014), the FS practitioner might need to design tasks that guide a learner towards the perception and action of a broad range of affordances that might otherwise be unseen. This process requires care and the realisation of individual differences as affordances that might be good for one person might equate to affordances as ill for another, if effectivities are not compatible. FS thus becomes a context whereby the person-environment relationship is emphasised and individuals learn to perceive and action a richer landscape of affordances than available in everyday life, which in turn helps an individual to realise further capacity for action and volition. 
For example, swings are common in most public parks which children frequent. In a FS session, a team of children could perceive the possibility of creating a swing by tying logs together with ropes and then attaching to a tree branch may also realise variations of log and rope combination. The role of the practitioner is to ensure that important individual and environmental characteristics are recognised in order to design tasks and/or interactions with the environment to enhance the important relational features in a manner that recognises the everyday life context of the learner (Brymer \& Davids, 2012). When viewed in this light, FS practice has the capacity to balance the relationship between people and the environment in a manner that enhances the well-being of both people and the environment (i.e., not using plastic swings).

Understanding and adopting an ED framework would allow FS practitioners and also trainers to contextualise experiences at a cultural and individual level to avoid a standardised, onesize-fits-all approach. Particularly relevant is the design of an affordance landscape, which involves inclusivity and an emphasis on different fields of affordances being available for exploration. From this perspective, FS could then become an essential provision in the current climate of formalised learning where time, safety and technology have contributed to limiting human interactions with the world around them and reducing the interactions with the landscape of affordances available.

\section{Working with constraints}

Working with task constraints is the easiest way to guide learning. This process can be as simple as ensuring that if a FS event has been designed to facilitate sustainable behaviours, then the activities chosen should represent sustainable practices in an everyday context. However, task manipulation might also happen during a predesigned activity in order to facilitate the learner's search for knowledge of the environment and for actions which can support the acquisition of this knowledge. This process should not be underestimated as manipulations undertaken carelessly lead to artificial learning environments which end up not being representative of behavioural contexts. The principles of representative design enable learners to attune to key information sources which act as affordances. Setting appropriate challenges for learners to pick up or become aware of various affordances can be confronting (Cordovil, Araújo, Pepping et al., 2015). A key skill is identifying the most 
important aspect that an individual needs to work on at any specific stage of his/her personal development. Practitioners must be able to identify whether manipulations will enhance the intended learning process or act as a rate limiter. This confirmation process needs to be ongoing as task constraints are dynamic, and due to the changing knowledge, skills and development of each individual, they can emerge and decay over time (Guerin \& Kunkle, 2004). Task manipulation is reliant on individual, group, environment and time.

As mentioned earlier, learning is viewed as a holistic journey which is ideally suited to understanding and instigating behavioural changes over a longitudinal timescale of learning i.e., months and years. In ED, the interplay between the learner, the educator, the task, the social context and the physical environment are considered essential to the learning process. This interaction is important because the learner is considered central to the experience and the interaction between the learner and the environment is a key relationship in the learning process. The ED perspective acknowledges that learning is not an isolated mental process and cannot be separated from the behavioural context since it emphasises the importance of providing experiences, as distinct from instructions, as a means of facilitating learning. FS activities must be carefully planned to accurately represent the relevant aspects of participant's everyday behavioural requirements.

FS programmes need to allow individuals to express their behaviours in relation to affordances designed into learning tasks. The emergent nature of learning and the notion that a learner self-organises (self-adjusts and adapts) suggests that FS practitioners cannot presuppose that there will be a single, specific response to a particular problem from each individual. The practitioner must also develop the communication skills to ensure he/she remains learner-centred throughout the whole learning experience. These expectations actually suit diverse physical, social and cultural settings.

FS practitioners who recognise the significance of affordances in an environment and then design learning activities and tasks will enrich the experiential processes, motivation, resilience and confidence aspects. Within the ED perspective, personal learning experiences that vary from individual to individual are more significant than measuring the development 
of social skills and empathy in a participant. As well, learning designing surpasses the current standardised structure of tools, fire, nature art and crafts, and team games.

A focus on affordances will benefit FS practice as it encourages a move away from the notion of a commercialised product, and instead emphasises a flexible way of doing any local culturespecific and philosophy-oriented learning activity in nature. Learning outside the classroom (such as udeskole) is not (yet) a brand or a technique. It is a way of learning by experience in childhood from diverse sources outside the four walls of a school building. Most children like to play and do engage in a variety of play when they have freedom, reduced adult control and fewer adult instructions (Sharma-Brymer \& Bland, 2016). Rather than seeing a particular model or programme 'developing' a child it should be that appropriate conducive environments be presented to children. Identifying the benefits of designing affordances will enhance the positive impact of FS for participants' overall health and well-being.

\section{Conclusion}

Increasingly, FS practice is becoming a product which conceals the influence of diverse cultural contexts, local and indigenous knowledges. FS practice in the UK would benefit from further theorisation that supports better understanding of learning design, taking into account individual and sociocultural needs. Basic notions of social construction help explain FS in its play and meaning-making processes, however a better understanding is enabled through awareness of affordances. We have presented aspects of an Ecological Dynamics framework in order to contextualise FS practice through this lens, highlighting how it supports better comprehension of the learner-centred approach via the realisation of affordances in the person-environment relationship. 


\section{References}

Aadland, H., Arnesen, T., \& Nerland, J. (2009). Friluftsliv in the Norwegian lower secondary school. In The birth of friluftsliv Conference Proceedings (H.Ibsen): A 150 year international dialogue. North Troendelag University College, Levanger, Norway, September 14-19. Available from: http://norwegianjournaloffriluftsliv.com/doc/132010.pdf, 1-14.

Araújo, D., \& Davids, K. (2011). What exactly is acquired during skill acquisition? Journal of Consciousness Studies, 18, 7-23.

Bentsen, P., Ho, S., Gray, T., \& Waite, S. (2017). A global view of learning outside the classroom. In Children learning outside the classroom (S. Waite). (Ed). $2^{\text {nd }}$ Edition. London: Sage, 53-66.

Bentsen, P., \& Jensen, F.S. (2012). The nature of udeskole: Outdoor learning theory and practice in Danish schools. Journal of Adventure Educaiton \& Outdoor Learning, 12(3), 199219.

Bentsen, P., Mygind, E. \&, Randrup, T. (2008). Towards an understanding of Udeskole: education outside the classroom in a Danish context. Paper presented at the 4th International Mountain and Outdoor Sports Conference, November 20th- 23, Hrubá Skála (CZ) Czech Republic, www.imosc.org.

Bruineberg, J. \&, Rietveld, E. (2014). Self-organization, free energy minimization, and optimal grip on a field of affordances. Frontiers in Human Neuroscience, 8(599), 1-14.

Brymer, E., \& Davids, K. (2012). Ecological psychology as a theoretical framework for development of sustainable behaviours towards the environment. Environmental Education Research, 1-19, DOI:10.1080/13504622.2012.677416

Brymer, E., \& Davids, K. (2014). Experiential learning as a constraints-led process: An ecological dynamics perspective. Journal of Adventure Education and Outdoor Learning, 14(2), 103-117.

Brymer, E., Davids, K. Mallabon, L. (2014) Understanding the psychological health and wellbeing benefits of physical activity in nature: An ecological dynamics analysis. Ecopsychology, 6, 189-197.

Brymer, E., \& Davids, K. (2016). Designing environments to enhance physical activity and psychological wellbeing. Sports Medicine, 46(7), 925-926.

Chow, J.-Y., Davids, K., Hristovski, R., Araújo, D., \& Passos, P. (2011). Nonlinear Pedagogy: Learning design for self-organizing neurobiological systems. New Ideas in Psychology, 29, 189200. 
Clough, P., Houge Mackenzie, S. \& Mallabon, E. \& Brymer, E. (2016). Adventurous physical activity environments: A mainstream intervention for mental health, Sports Medicine, 46(7), 963-8.

Cordovil, R., Araújo, D., Pepping, G-J., et al. (2015). An ecological stance on risk and safe behaviors in children: The role of affordances and emergent behaviors. New Ideas in Psychology, 36: 50-9.

Cree, J., \& McCree, M. (2012). A brief history of FS in the UK-Part 2. Horizons, No.62, www.outdoor-learning.org.

Davids, K., Button, C., \& Bennett, S.J. (2008). Dynamics of skill acquisition: A constraints led approach. Champaign, IL: Human Kinetics.

Davids, K., Araújo, D., \& Brymer, E. (2016) Designing affordances for physical activity: An ecological dynamics perspective. Sports Medicine, 46(7), 933-938.

Davies, G. (2013, January 2). History of Forest School. Retrieved from http://www.forestschoolassociation.org/history-of-forest-school/

Dunwoody, P. T. (2006). The neglect of the environment by cognitive psychology. Journal of Theoretical and Philosophical Psychology, 26, 139-153.

Ewert, A.W., Sibthorp, J. \& Sibthorp, R. J. (2014). Outdoor adventure education: Foundations, theory, and research. Champaign: Human Kinetics.

Forest School Association. History of Forest School. http://www.forestschoolassociation.org/history-of-forest-school/. Accessed 12/9/2016

Forest School Education. https://forestschools.com/wp-content/uploads/2012/09/FSEForest-Schools-Leader-Level-3-2016.pdf. Accessed 10/4/2017

Gelter, H. (2000) Friluftsliv: The Scandinavian philosophy of outdoor life. Canadian Journal of Environmental Education. [Online] 5, 77 - 90. Available from: http://jee.lakeheadu.ca/index.php/cjee/article/viewFile/302/222

Gelter, H. (2009). Friluftsliv as slow and peak experiences in the transmodern society. Henrik Ibsen: The Birth of "Friluftsliv", A 150 Year International Dialogue Conference Jubilee Celebration. North Troendelag University College, Levanger, Norway. September 14-19.

Gibson, J. (1979). The ecological approach to visual perception. Hillsdale, New Jersey: Lawrence Erlbaum Associates.

Gill, T. (2007). No fear: growing up in a risk averse society. London: CalousteGulbenkian Foundation. 
Goleman, D. (1998). Working with Emotional Intelligence. London: Bloomsburry Publishing Plc.

Guerin, S., \& Kunkle, D. (2004). Emergence of constraint in self-organized systems. Nonlinear Dynamics, Psychology and Life Sciences, 8, 131-146.

Gurholt K. (2014). Joy of nature, friluftsliv education and self: combining narrative and cultural-ecological approaches to environmental sustainability. Journal of Adventure Education and Outdoor Learning, 14(3), 233-246.

Harris, F. (2017). The nature of learning at FS: Practitioners' perspective. Education, 3-13, 45(2), 272-291.

Hart, V., Whatman, S., McLaughlin, J., \& Sharma-Brymer, V. (2012). Pre-service teachers' pedagogical relationships and experiences of embedding Indigenous Australian knowledge in teaching practicum. Compare: A Journal of Comparative and International Education, 42(5), 703-723.

Hughes, B. (2002). A Playworker's taxonomy of play type. 2nd edition. London: PlayLink.

Jordet, A. (2009). What is outdoor learning? In OUTLiNES: Outdoor learning in elementary schools, from grassroot to curriculum in teacher education. A didactic manual developed by Comenius Project, European Commission.

Knight, S. (2009). Forest Schools and outdoor learning in the early years. London: Sage Publications Inc.

Knight, S. (2011). Forest School as a way of learning in the outdoors in the UK. International Journal for Cross-Disciplinary Subjects in Education (IJCDSE), 1(1), 590-595.

Laevers, F. (1999). The project Experiential Education. Well-being and involvement make the difference. Early Education, 27.

Leather, M. (2016). A critique of Forest School: Something lost in translation. Journal of Outdoor and Environmental Education, 2-11.

Maitney, P. T. (2002). Mind in the Gap: Summary of research exploring 'inner' influences on pro-sustainability learning and behaviour. Environmental Education Research, 8(3), 299-306.

Massey, S. (2005). The benefits of a Forest School experience for children in their early years. Action Research, Topic 33, 27-34.

Maynard, T. (2007). Forest Schools in Great Britain: An initial exploration. Contemporary Issues in Early Childhood, 8(4), 320-331.

Muñoz, S. A. (2009). Children in the outdoors: a literature review. Sustainable Development Research Centre. http://www.countrysiderecreation.org.uk/Children\%200utdoors.pdf 
Newell, K. M. (1986). Constraints on the development of co-ordination. In M. G. Wade \& H. T. A. Whiting (Eds.), Motor development in children: Aspects of co-ordination and control. Dodrech: Martinus Nijhoff.

O’Brien, L., \& Murray, R. (2006). A marvellous opportunity for children to learn: A participatory evaluation of Forest School in England and Wales. Surrey, England: Forest Research, 52 pages.

O'Brien, L., \& Murray, R. (2007). Forest School and its impacts on young children: Case studies in Britain. Urban Forestry \& Urban Greening, 6, 249-265.

O'Brien, L. (2009). "Learning outdoors: The Forest School approach." Education, 3-13 37(1), 45-60.

Pinder, R. A., Davids, K., Renshaw, I., \& Araújo, D. (2011). Representative learning design and functionality of research and practice in sport. Journal of Sport and Exercise Psychology, 33, 146-155.

Playwork. http://www.playwales.org.uk/eng/playwork.

Rietveld E., \& Kiverstein, J. (2014). A rich landscape of affordances. Ecological Psychology, 26, 325-52.

Roe, J. \& Aspinall, P. (2011). The emotional affordances of forest settings: an investigation in boys with extreme behavioural problems. Landscape Res, 36 (5), 535-552.

Said, I. (2012). Affordances of nearby forest and orchard on children's performances. Procedia Soc Behav Sci, 38, 195-203.

Sharma-Brymer, V. \& Bland, D. (2016). Bringing Nature to schools to promote children's physical activity. Sports Medicine, 46(7), 955-62.

Sharma-Brymer, V., Brymer, E. \& Davids, K. (2015). The relationship between physical activity in green space and human health and wellbeing: an ecological dynamics perspective. Journal of Physical Education Research, 2 (I), 7-22.

Stewart, A. (2008). Whose place, whose history? Outdoor environmental education pedagogy as 'reading' the landscape. Journal of Adventure Education and Outdoor Learning, 8(2), 79-98.

Stoffregen, T. A. (2003). Affordances as properties of the animal-environment system. Ecological Psychology, 15(2), 115-134.

Waite, S., Bølling, M. \& Bentsen, P. (2016) Comparing apples and pears? A conceptual framework for understanding forms of outdoor learning through comparison of English Forest Schools and Danish udeskole. Environmental Education Research, 22(6). 
Whap G. (2001). A Torres Strait Islander perspective on the concept of Indigenous Knowledge. Australian Journal of Indigenous Education, 29(2), 22-29.

Withagen, R., De Poel, H.J., Araújo, D., \& Pepping, G. (2012). Affordances can invite behaviour: Reconsidering the relationship between affordances and agency. New Ideas in Psychology, 30(2), 250-258. 